\title{
Pediatric Coronary Allograft Vasculopathy-A Review of Pathogenesis and Risk Factors
}

\author{
Kurt R. Schumacher, MD, ${ }^{*}$ Robert J. Gajarski, MD, ${ }^{*}$ and Simon Urschel, $M D^{\dagger}$ \\ ${ }^{*}$ Congenital Heart Center, University of Michigan, Ann Arbor, Mich, USA; †Pediatric Cardiology and Heart Transplant \\ Program, University of Alberta, East Edmonton, Alberta, Canada
}

\begin{abstract}
A B S T R A C T
Coronary allograft vasculopathy is the current leading cause for late graft loss following cardiac transplantation. Its pathogenesis is multifactorial, including immune, constitutional and genetic factors, metabolism, infection, as well as potential injury from routine immunosuppressive therapy. Children represent a patient group with unique differences: their pretransplant history rarely includes ischemic heart disease and risk factors for atherosclerotic heart disease, but many are presensitized from use of allograft material during reconstructive cardiac surgeries. Compared with older children and adults, infants and young children show significantly lower rates of graft vasculopathy that may be related to the relative immaturity of their immune system.

This review summarizes the current concepts of coronary allograft vasculopathy derived mainly from animal models and adult clinical observations. It provides an overview of confirmed risk factors and explains their interactions. The characteristics and unique clinical findings among pediatric transplant recipients will be explored within the context of recent, albeit limited, scientific investigations.
\end{abstract}

Key Words. Heart Transplant; Coronary Vasculopathy; Polymorphisms

\section{Introduction}

$\mathrm{C}$ oronary allograft vasculopathy (CAV) is an accelerated form of arteriopathy affecting the coronary vessels of both pediatric and adult heart transplant (HTx) recipients. ${ }^{1,2}$ It is characterized by heterogeneous intimal proliferation, medial wall thickening, and progressive luminal stenosis. ${ }^{3-5}$ Despite recent improvements in early and midterm post-HTx survival, CAV develops in approximately one third of pediatric patients within 10 years of transplant and continues to be an immutable barrier to longer-term graft survival. ${ }^{6}$ This review will outline the current pathophysiologic understanding of this complex disease process and detail commonly reported constitutional, infectious, and immunogenetic risk factors in order to provide a framework from which current therapies have been and may be developed. While much of the following discussion will focus on pediatric risk factors, the reader should be cognizant that published data on childhood risk factors is less robust than in adults. Therefore, some factors may be notably absent not because they are necessarily irrelevant in pediatrics, but

Congenit Heart Dis. 2012;7:312-323 rather because of limited data or an unknown association with disease.

\section{CAV Pathogenesis}

CAV shares many aspects of its pathogenesis and many risk factors with arteriosclerosis of the nontransplanted heart. ${ }^{3}$ In adults, ischemic heart disease is the leading cause necessitating heart transplantation. In these patients, the partial persistence of the atherosclerotic process after transplantation partly explains the higher frequency of CAV compared with children. However, the difference in incidence is only marginal when comparing adults with teenagers, an age group that in nontransplanted individuals usually does not experience significant atherosclerotic vascular disease. $^{7}$

In addition to these constitutional factors, which include mainly genetic and metabolic predispositions, a large contribution to CAV stems from the immune response toward an immunologically foreign organ. The operative procedure of transplantation from a deceased donor enhances 


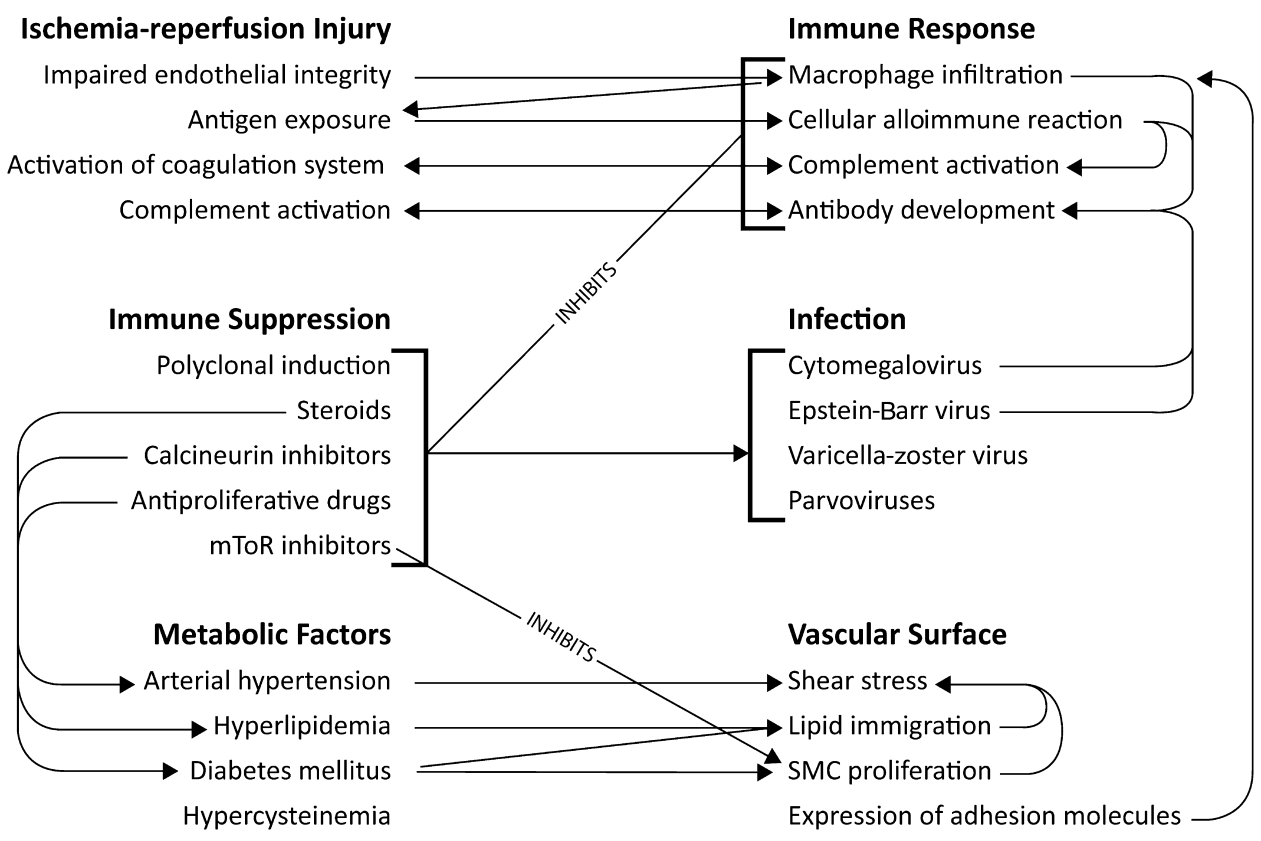

Figure 1. Overview of the pathogenetic factors of CAV and their interaction: Arrows symbolize enhancing effects, bars inhibition. Ischemia-reperfusion injury includes damage to the endothelium facilitating macrophage invasion and leading to exposure of graft antigens and activation of the complement system. This triggers an early response of the adaptive immune system, which is enhanced if preformed graft specific antibodies are present, but also yields their development if no appropriate immune suppression is introduced. Adverse effects of the immune suppressants include enhancement of constitutional factors of atherosclerosis and increased risk for infections with negative impact on CAV. Viral infections under immune suppression may enhance antibody production (Epstein-Barr virus) and have additional direct effects on endothelium integrity (cytomegalovirus). Formation of plaques in the lumen perpetuates itself through increasing shear stress and further disturbance of the endothelial integrity and subsequent enhanced immune response. mTOR inhibitors have antiproliferative effects on small muscle cell delaying the progression of graft vasculopathy. For details, see text.

this response. To further complicate matters, immunosuppressive medications and certain infectious complications of immune suppression also contribute to CAV pathogenesis. These factors show significant overlap and interaction as schematically shown in Figure 1 and detailed in the following sections.

\section{Ischemia-reperfusion Injury and Early Immune Activation}

The process of CAV in HTx recipients can be traced to the time of graft transplantation when donor-derived factors, which may likely contribute to future CAV, have already been activated. ${ }^{8}$ Because the basis for heart donation is brain death, the vast majority of donated hearts have undergone a period of significantly impaired circulation and oxygen delivery often including a cardiac arrest. Inotropic support and fluctuations of the blood pressure are common, if only transiently, in many patients. Subsequent apoptotic processes in the tissue and activation of the donor immune system and coagulation are initiated, including complement, macrophages, and thrombocytes. In addition, the process of brain death is associated with multiple neurohormonal changes that may adversely affect the coronary endothelium. Immediately following brain death, circulating plasma catecholamines markedly rise resulting in an imbalance between oxygen delivery and consumption. ${ }^{9,10}$ The resulting ischemic damage to the graft leads to impaired integrity of the endothelium and activation of the innate immune system ${ }^{11}$ causing endothelial alteration that persists postHTx. ${ }^{12,13}$ Following organ harvest, a period of cold ischemia further contributes to this process and especially enhances the disturbance in the endothelial cell function and the vessel wall integrity. ${ }^{14}$ In animal models, loss of smooth muscle cells (SMCs) in the intima media at this stage is significantly associated with the degree of later CAV.$^{15} \mathrm{~A}$ 
recent study observed the SMC reduction to occur in two waves, one at the initial day post-HTx and one 7 days later. ${ }^{16}$ The decrease of SMC density occurred significantly less in absence of neutrophil granulocytes (NCs).

These models confirm the current understanding of the early events: preexplantation damage and preservation-associated ischemia induce disturbed integrity of the endothelial barrier ${ }^{17}$ promoting invasion of components of the innate (NCs, macrophages) and adaptive immune system in both donor and recipient. ${ }^{4,18}$ Apoptosis occurs in various cells in the intima yielding exposure of human leukocyte antigen (HLA) and other antigens ${ }^{17}$ that are recognized and processed by the recipient adaptive immune system including both CD 8 and CD4 positive T cells ${ }^{18}$ and B cells. ${ }^{19} \mathrm{At}$ the same time, a highly immunogenic environment persists within the graft through activation of the complement and the coagulation system and secretion of cytokines and chemotactic factors by the injured endothelium. ${ }^{14}$ Microscopic changes within the vascular wall accompanying these processes include interstitial fibrosis, invasion of NC, macrophages and lymphocytes, primarily reduced numbers and secondarily increased proliferation of SMC, and infiltration of lipids with formation of foam cells. ${ }^{4,16}$

\section{Mechanical Factors and Atherosclerotic Impact}

Once changes are initiated, the vessel narrowing, plaque development, and local activation of thrombocytes perpetuates the endothelial injury. Shear stress associated with the altered vessel geometry and perfusion hemodynamics is further enhanced by increased arterial blood pressures. ${ }^{20-22}$ The latter is a very common finding in post-HTx patients. In children, hypertension is often attributed to the immunosuppressive medication (steroids, calcineurin inhibitors [CNI] $)^{23}$ but is also due to progressive renal impairment as observed in the majority of patients.

Mammalian target of rapamycin inhibitors sirolimus and everolimus play an ambivalent role in the pathogenesis of CAV: their antiproliferative capacity does not only impair the adaptive immune response but additionally reduces proliferation of SMC and NC, hampering the progression of the vascular narrowing. On the flipside, particularly in combination with CNI, the majority of patients experience an unfavorable shift in plasma triglyceride and cholesterol levels and profile, ${ }^{23}$ increasing the risk for development of atheroma-associated vasculopathy. Similar concerns accompany other immune suppressive agents. As described previously, steroids and CNI induce hypertension in a significant proportion of patients through direct effects but also secondary to renal injury. Both drugs may also alter metabolism leading to less favorable lipid profiles and development of diabetes mellitus. ${ }^{23}$ However, the use of synergistic effects in combined immunosuppressive regimens was found to reduce incidence of $\mathrm{CAV}^{24-26}$ with the latest trials showing less new development and progression of CAV when combining a CNI with an mammalian target of rapamycin inhibitor compared with mycophenolate. ${ }^{27}$ The adverse effect of infection, particularly virusinduced enhanced generation of antibodies against the graft, will be discussed later. Finding the right balance between sufficient immune suppression and adverse effects of the medication is therefore crucial, but often challenging.

\section{Chronic Rejection and Antibody-mediated Immune Response}

In any organ transplantation not originating from an identical twin, the alloimmune response occurs from the moment of reperfusion of the organ. Significant concentrations of preformed antibodies against the donor HLA or blood group antigens induce immediate massive activation of all arms of the immune system, a situation clinically experienced as "hyperacute rejection." Antibodymediated activation of the complement system leads to direct graft damage but also chemotaxis, attracting antigen presenting cells as well as lymphocytes including CD8+ cytotoxic T cells. Surfaces covered in antibodies are opsonized to antigen presenting cells facilitating activation of the adaptive immune system. This includes generation of antigen specific CD4+ T cells, B cells, and plasma cells and yields further antibody production and direct cytotoxic effects on the graft.

Consistent with findings in adults ${ }^{28}$ and other transplanted organs, ${ }^{29}$ clinical studies in heart transplanted children found not only a higher mortality in presence of donor-specific HLA antibodies (DSAs) but a higher incidence and accelerated progression of $\mathrm{CAV}^{30-33}$ Compared with adults, development of DSA is less frequent in children and associated with older age at transplant. ${ }^{34}$

Multiple investigators have linked acute allograft rejection with pediatric $\mathrm{CAV},{ }^{24,35}$ particularly recurrent rejection during the first post-HTx 
year. ${ }^{2,36}$ In the Pediatric Heart Transplant Study group analysis, Pahl and colleagues found that two or more episodes of acute rejection in the first year correlated with $\mathrm{CAV}^{37}$ Late rejection $(>1$ year post-HTx), including that associated with hemodynamic compromise, is also a well-established risk factor for CAV development. ${ }^{2,24,36,38-40}$ In a large, single-center experience, Mulla and colleagues reported that both frequent (regardless of severity) and severe episodes (even in the absence of other rejection episodes) of late rejection are independent predictors of CAV development, and the resulting CAV can have a rapid onset and accelerated course. ${ }^{38}$

Most of these studies have not investigated the presence of DSA in their patient cohorts. Development of DSA is associated with the frequency of acute cellular rejection. ${ }^{41}$ In part, the detrimental effect of repeated acute cellular rejection may be mediated through de novo DSA. However, graft vasculopathy occurs in absence of DSA. The development of DSA as well as repeated acute rejection may both be surrogates for insufficient suppression of the immune system. Every episode of rejection will, to some extent, result in an episode of vascular damage comparable with the previously described cascade during reperfusion and the early post-HTx phase.

\section{Genetic Predispositions}

Variations in small sections of DNA, including single nucleotides, between individuals that occur with some regularity in the human populationtypically at least $1 \%$ - are known as genetic polymorphisms. ${ }^{42}$ The presence of a polymorphism does not imply that it is pathologic, and much research is currently ongoing to determine which of these naturally occurring genetic variations may be disease-causing. In recent years, an increasing awareness of potentially pathologic polymorphisms affecting the inflammatory response has led to several publications describing the role of polymorphisms in determining the risk of CAV. Because there have been no large-scale pediatric publications examining polymorphisms and CAV, the following discussion will review currently available adult data assuming some pediatric relevance to encourage new hypothesis-driven investigations.

\section{Immune System Polymorphisms}

Intracellular adhesion molecule-1 (ICAM-1) is an adhesion molecule present on the surface of leukocytes and endothelial cells. When stimulated by inflammatory cytokines, ICAM-1 expression is markedly increased. ${ }^{43}$ When Borozdenkova et al. studied ICAM-1 polymorphisms in both HTx donors and recipients, they found that donor hearts expressing a particular ICAM-1 polymorphism had significantly decreased incidence of CAV at 2 years post-orthotopic heart transplant. ${ }^{44}$

Interleukin-6 (IL-6) is a proinflammatory cytokine released by myocardial and endothelial cells. ${ }^{45,46}$ It has many effects that may contribute to the development of CAV including SMC growth, ${ }^{47}$ production of C-reactive protein, ${ }^{48}$ modulation of endothelial permeability, ${ }^{49}$ and triggering neutrophil oxidative burst. ${ }^{46}$ The IL-6 gene is known to be polymorphic with a single nucleotide exchange resulting in a phenotype with increased IL-6 production. ${ }^{50}$ Densem and colleagues sequenced adult HTx recipients and found that being homozygous for the high-production IL-6 allele was significantly associated with an earlier onset of CAV. ${ }^{51}$

Transforming growth factor-beta 1 (TGF- $\beta 1$ ) is a cytokine that influences the accumulation and function of leukocytes and fibroblasts at sites of injury while enhancing production of extracellular matrices, ${ }^{52}$ which may contribute to the development of CAV. However, TGF- $\beta 1$ also inhibits smooth muscle and endothelial cell proliferation, ${ }^{53}$ which may be protective against CAV. The gene encoding TGF- $\beta 1$ has multiple polymorphisms, and, as such, reports on the effects of these polymorphisms are contradictory. Holweg and colleagues found that in HTx recipients, a specific polymorphism at locus site +869 was a risk factor for accelerated CAV, while a polymorphism at locus site +915 was not a significant predictor. ${ }^{52} \mathrm{To}$ the contrary, Densem and colleagues found directly opposing results. ${ }^{54}$ The explanation for this discrepancy is unclear, but nevertheless, TGF- $\beta 1$ appears to have a role in the pathogenesis of $\mathrm{CAV}$, and additional studies may further elucidate its significance.

Tumor necrosis factor-alpha $(\mathrm{TNF}-\alpha)$ is a cytokine released primarily by macrophages that initiates a host of responses that can precipitate coronary endothelial dysfunction, ${ }^{55,56}$ and some CAV patients have been found to have high levels of circulating TNF- $\alpha .{ }^{57}$ However, when Densem and colleagues evaluated the influence of TNF- $\alpha$ polymorphisms on CAV development, they found no relationship between recipient or donor genotype and CAV development, despite a significant proportion of recipients and donors having high 
TNF- $\alpha$ producing genotypes. ${ }^{55}$ In contrast, Ternstrom and colleagues studied recipient TNF- $\alpha$ and its linked cytokine gene, TNF- $\beta,{ }^{58}$ finding an increased CAV prevalence and decreased 3-year post-HTx survival among patients homozygous for high cytokine producing polymorphisms of either TNF- $\alpha$ or TNF- $\beta$. The discrepant results between the two studies may be due to methodologic differences. While more compelling data is needed, polymorphisms in TNF- $\alpha$ and TNF- $\beta$ could become important pretransplant markers with TNF- $\alpha$ suppression as a potential therapeutic target in at-risk recipients.

\section{Coagulation and Thrombocyte Activation}

Alterations in fibrinolytic activity may also be important in CAV intimal proliferation as the involved enzymes promote vascular cell migration, cellular infiltration, and matrix regeneration. ${ }^{59}$ Enhanced fibrinolytic activity can result from excessive tissue plasminogen activator (TPA) or decreased activity of plasminogen activator inhibitor-1 (PAI-1), a TPA inhibitor. ${ }^{60}$ Polymorphisms of both the TPA and PAI-1 genes have been previously described. ${ }^{60-62}$ In one such study, Benza and colleagues $^{60}$ found significantly increased freedom from CAV at 24 months for PAI-1 high-expression homozygotes (100\% freedom) and heterozygotes (92\%) compared with low expression homozygotes $(45 \%)$. No association was found between TPA polymorphisms and CAV. In a recent follow-up study, the same investigators corroborated their previous findings and demonstrated severe CAV in transplanted PAI-1 knockout mice. ${ }^{59}$ Thus, PAI-1 activity appears to prevent CAV development and may be a future therapeutic target.

Platelet-derived growth factor (PDGF) and vascular endothelial growth factor (VEGF) both regulate differentiation of vascular progenitor cells. ${ }^{63}$ PDGF regulates progenitor cell differentiation into SMCs, while VEGF regulates differentiation into endothelial cells. Both factors may contribute to $\mathrm{CAV}$ pathogenesis by expanding sites of coronary injury through smooth muscle and endothelial cell proliferation. ${ }^{64}$ Both genes have polymorphisms at multiple sites. ${ }^{65,66}$ Tambur and colleagues ${ }^{64}$ recently demonstrated that specific PDGF and VEGF polymorphisms were significantly associated with an increased incidence of CAV and decreased 3-year patient survival. ${ }^{64}$

The renin-angiotensin system has been postulated to be a significant contributor to the pathogenesis of $\mathrm{CAV}^{67}$ and inhibition of the renin-angiotensin system is now standard therapy to prevent progression of CAV. ${ }^{68,69} \mathrm{~A}$ component of that system, angiotensin converting enzyme (ACE) has well-recognized polymorphisms, ACE-D and ACE-I, in humans, ${ }^{70}$ and a specific genotype (ACE-DI) may increase atherosclerotic coronary disease and myocardial infarction in non-HTx adults. ${ }^{71,72}$ Pethig and colleagues ACE genotyped 146 patients and serially assessed them for onset and progression of CAV finding that the three ACE genotypes had differing freedoms from CAV by 6 years post-HTx. ${ }^{73}$ In ACE-II and ACE-DI patients, freedom from CAV was $85 \%$ and $77 \%$, respectively, while ACE-DD patients had only a $55 \%$ freedom from CAV $(P=$ $0.015)$. Cunningham and colleagues ${ }^{74}$ evaluated donor ACE polymorphisms and found ACE-DI grafts had significantly increased prevalence of $\mathrm{CAV}^{74}$

\section{Clinical Relevance}

The current role of genetic polymorphisms in clinical decision making is very limited, and, with few exceptions, the study of polymorphisms has been limited to single genes. However, multiple inflammatory pathways and cytokines interact during the inflammatory response. Given the complex interplay and high level of redundancy of the immune system, understanding how a single polymorphism modulates expression of a single cytokine adds little to understanding how the inflammatory cascade affects CAV pathogenesis. Until studies evaluate large numbers of patients comparing both genetic and nongenetic risks of $\mathrm{CAV}$, the clinical utility of polymorphisms for risk stratification or treatment guidance will remain limited.

\section{Metabolism}

While hypercholesterolemia is a risk factor for $\mathrm{CAV}$ in adult patients and treatment with statins may ameliorate its effects, ${ }^{75}$ cholesterol levels have not been associated with CAV in pediatric patients. Nonetheless, hypercholesterolemia is prevalent in pediatric HTx patients, particularly those on cyclosporine immunosuppression, and statin therapy decreases both low-density lipoprotein cholesterol and total cholesterol levels in these patients. ${ }^{76,77}$ In a single-center study by Mahle and colleagues, treatment with pravastatin in post-HTx children was associated with a lower incidence of CAV. ${ }^{39}$ As high low-density lipoprotein cholesterol has been associated with coronary disease in adults, including CAV, so, too, has low 
high-density lipoprotein cholesterol. ${ }^{78,79}$ A recent, small pediatric study demonstrated an association between low serum levels of high-density lipoprotein cholesterol and CAV in patients already on statin therapy ${ }^{80}$ However, small patient numbers and an abnormally early onset of CAV in these study patients limit the generalizability of these results to a larger pediatric $\mathrm{HTx}$ population. While the relative contribution of cholesterol chemistry to pediatric CAV is unclear, because of the beneficial effects of statins on CAV noted in adult studies their use has nevertheless become routine in many pediatric transplant centers.

Finally, elevated plasma homocysteine (Hcy) levels are a recognized independent risk factor for coronary atherosclerosis. ${ }^{81-83}$ Both adult and pediatric HTx patients have been demonstrated to have elevated plasma Hcy. ${ }^{84,85}$ Further, adult HTx recipients with severe CAV have significantly higher plasma Hcy levels when compared with HTx recipients without evidence of CAV. ${ }^{86,87} \mathrm{No}$ association between pediatric Hcy levels and CAV has been established. The exact mechanism through which Hcy affects CAV remains unclear; however, Hcy is known to damage vascular endothelium through prooxidative pathways leading to impaired endothelial vasodilation and intimal hyperplasia. ${ }^{86,88,89}$ Treatment of both adult and pediatric patients with folic acid has been shown to decrease Hcy levels in patients with abnormally high Hcy levels. ${ }^{90,91}$ In adults, this led to improved survival 7-years posttreatment, although the benefit may not be exclusively related to a decrease in cardiovascular events. ${ }^{92}$ Hcy and treatment of hyperhomocysteinemia warrant further study in pediatric CAV.

\section{Infection}

\section{Cytomegalovirus Infection}

The role of cytomegalovirus (CMV) infection in pediatric CAV remains controversial. CMV may contribute to atherosclerotic plaques by modulating chronic inflammation in arterial walls. ${ }^{93} \mathrm{~A}$ similar process may contribute to CAV lesions in transplanted patients. In adults, multiple studies have demonstrated an increased risk of CAV after both CMV seroconversion and symptomatic CMV infection. ${ }^{94-97}$ Notably, most adult data cites "CMV mismatch," a CMV-negative recipient of a $\mathrm{CMV}$-positive heart, as a CAV risk factor. A large, single-center retrospective pediatric study demonstrated that recipients who are $\mathrm{CMV}$-positive prior to transplant have a significantly higher rate of $\mathrm{CAV}^{98}$ Post-HTx CMV replication appears to impair recipient endothelial function, and this may provide a substrate for the development and progression of $\mathrm{CAV}^{99}$ A recent clinical study evaluating intravascular ultrasound as a modality to detect CAV found that CMV-positive patients had significantly increased coronary maximal intimal thickness compared with $\mathrm{CMV}$-negative patients. ${ }^{35}$ To the contrary, a recent multicenter study of 1568 patients from the Pediatric Heart Transplant Study group found no correlation between donor or recipient CMV status and CAV. ${ }^{100}$ These discrepant results may be partially explained by differences in the proportion of infants in each study, differences in CMV prophylaxis and differences in CAV detection methods. A definitive role for CMV infection in the pathogenesis of pediatric CAV remains unclear.

\section{Non-CMV Viral Endomyocarditis}

Other viral endomyocardial infections have also been associated with CAV. In a large study of pediatric $\mathrm{HTx}$ patients, polymerase chain reaction identification of viral genome in myocardial biopsies, particularly adenovirus, was associated with adverse clinical events including increased rejection, graft loss, and early CAV development. ${ }^{101,102}$ Moulik and colleagues recently found that viral endomyocardial infection is an independent predictor of graft loss in children likely secondary to premature development of CAV ${ }^{103}$ Historically, many of these viruses have been causally linked to acute rejection that can accelerate CAV (as previously described). It is unclear whether the viruses themselves led to the development of CAV, or if CAV was indirectly associated with virally mediated rejection. In the study by Moulik et al., parvoviral endomyocarditis was not associated with rejection but was a significant risk factor for CAV. ${ }^{103}$ The precise mechanisms by which viral infections are associated with CAV, whether independent of rejection or not, remain elusive. However, many investigators suspect these active myocardial viruses may lead to an inflammatory state that potentiates ongoing coronary inflammation and subsequent CAV. In this setting, natural killer (NK) cells may be important mediators of CAV. Graham and colleagues developed a model for CAV using post-HTx mice that lacked functioning B and T cells. ${ }^{104}$ Virally infected mice subsequently developed CAV, while noninfected mice did not. Furthermore, infected mice in which NK cells were depleted had a significantly lower inci- 
dence of CAV supporting the role of NK cells in virally mediated CAV development.

\section{Constitutional Factors}

\section{Hypertension}

Hypertension is a well-established risk factor for cardiovascular disease in adults. ${ }^{105,106}$ In concordance with the pathophysiologic mechanisms described previously, hypertension is significantly associated with CAV in post-HTx adults, ${ }^{107}$ and treatment with antihypertensive medication delays CAV progression. ${ }^{108}$ Despite the lack of published data for pediatric CAV, given its strong association with coronary disease in other populations, blood pressure control is a mainstay of post-HTx therapy.

\section{Age}

Compared with adults, the cited incidence of CAV is lower in children with reported 5-year freedom from CAV of $50 \%{ }^{109}$ and $85 \%{ }^{110}$ in adult and pediatric transplant recipients, respectively. Pahl and colleagues demonstrated that recipient age was a relative risk for CAV. They found that a patient aged $\geq 12$ years at transplant had a 2.9-fold increased likelihood of developing CAV compared with a child transplanted at $\leq 5$ years. ${ }^{37}$ This corroborates data from other studies showing an increased incidence of CAV among older age transplant patients. ${ }^{40}$ The incidence of CAV in adolescent patients is similar to adults. ${ }^{6}$ As a corollary, there is a lower risk of CAV in infant transplant recipients. ${ }^{35,111}$ The higher freedom from CAV in pediatric patients may be related to a lack of donor/recipient atherosclerotic risk factors or preexisting coronary endothelial injury that usually predisposes adult patients to an increased incidence of disease. ${ }^{7}$ As such, older donor age has also been recognized as a risk for pediatric CAV with incremental increases as donor age increases to an ultimate threefold increase if using donors $>30$ years old compared with younger donors. ${ }^{37}$ This may be partially attributable to older donors frequently having increased cardiovascular risk factors for atherosclerosis, but in addition, intact immune function within the donor myocardium may affect endothelial function after transplantation thereby increasing the potential for donormediated CAV. ${ }^{37}$ Detection methods may also affect reported frequencies of disease as widespread use of intravascular ultrasound has significantly increased detection rates among adult patients.

Pediatric patients, especially infants and toddlers, are immunologically privileged in the setting of organ transplantation due to various immaturities of the immune system reflected in an annual CAV incidence of only $3 \%$ in children transplanted in the first year. ${ }^{6}$ Children demonstrate a decreased incidence of immune-mediated endothelial injury, ${ }^{7}$ lack immune memory, ${ }^{112}$ are unable to mount T-independent B cell immune responses under 2 years old, ${ }^{113}$ are less likely to develop donor-specific HLA antibodies post$\mathrm{HTx}^{34}{ }^{34}$ and are able to persistently tolerate blood group incompatible organs. ${ }^{114,115}$ Thymectomy, which routinely occurs in children with congenital heart disease for reasons of surgical access, may also contribute to the better graft acceptance of infant recipients. The thymus plays a crucial role in the development of adaptive immunity and selftolerance, and this procedure alters the total number and the phenotype of $\mathrm{T}$ cells for many years. ${ }^{116,117}$

\section{Retransplantation}

Although patients retransplanted for CAV fare better than those retransplanted for early graft failure, overall survival after pediatric retransplantation is inferior to survival after primary transplant. ${ }^{118}$ The International Society for Heart and Lung Transplantation 2010 pediatric HTx report found that retransplantation was significantly associated with early onset CAV. ${ }^{6}$ The reasons for this are not completely clear; however, the proportion of sensitization against HLA or minor antigens is likely higher due to the exposure to nonself-antigens and the previous development of a "successful" immune response against the first graft. Further, the higher likelihood of cofactors having developed through years of immune suppression and associated adverse events may contribute. In particular, children with early graft failure show poor graft survival following retransplantation in registry data; ${ }^{6}$ however, this is likely impacted by their overall poorer clinical condition going into the surgery.

\section{Summary}

CAV pathogenesis represents the complex interplay of a variety of factors. Medical intervention for one factor may increase the risk of another developing or worsening. Close monitoring of the various contributors to $\mathrm{CAV}$ is required and therapy must be adapted to changes in the balance of risk factors. The intensity of immune suppression needs to be carefully balanced with potential adverse effects of the medication. Contribution of 
altered lipid profiles, arterial hypertension, and diabetes mellitus, whether caused by genetic predisposition or subsequent to medication, have to be addressed by appropriate medication. Infectious disease monitoring as adapted in the recent decade allows more timely intervention when required. Donor-specific antibodies represent a major contribution to $\mathrm{CAV}$; however, despite increasing evidence that acute antibody-mediated rejection can successfully be treated with invasive antibody removal and therapies to inhibit antibody development, the impact of these treatments on the progression of CAV remains indeterminate.

CAV remains the leading challenge for longterm graft survival. An incomplete understanding of its pathogenesis has limited the development of therapies directed at process reversal or avoidance. Further study, particularly in the pediatric HTx population, is necessary to better elucidate mechanisms of disease and potential targets for future therapeutic intervention.

\section{Author Contributions}

Dr. Schumacher was responsible for article concept and design, comprehensive review of the literature, drafting the article, and critical revision of the article.

Dr. Gajarski was responsible for article concept and design and critical revision of the article.

Dr. Urschel was responsible for article concept and design, comprehensive review of the literature, drafting the article, and critical revision of the article.

Corresponding Author: Kurt R. Schumacher, MD, University of Michigan Congenital Heart Center, Pediatric Heart Transplant Program, 1500 E Medical Center Dr, L1242 Women's, SPC 5204, Ann Arbor, MI 48109, USA. Tel: (734) 232-3945; Fax: (734) 232-3744; E-mail: kurts@med.umich.edu

Conflict of interest: The authors have no conflict of interest to disclose.

Accepted in final form: October 24, 2011.

\section{References}

1 Pahl E, Fricker FJ, Armitage J, et al. Coronary arteriosclerosis in pediatric heart transplant survivors: limitation of long-term survival. 7 Pediatr. 1990;116:177-183.

2 Hathout E, Beeson WL, Kuhn M, et al. Cardiac allograft vasculopathy in pediatric heart transplant recipients. Transpl Int. 2006;19:184-189.
3 Colvin-Adams M, Agnihotri A. Cardiac allograft vasculopathy: current knowledge and future direction. Clin Transplant. 2011;25:175-184.

4 Billingham ME. Histopathology of graft coronary disease. 7 Heart Lung Transplant. 1992;11(3 pt 2):S38-S44.

5 Tuzcu EM, De Franco AC, Goormastic M, et al. Dichotomous pattern of coronary atherosclerosis 1 to 9 years after transplantation: insights from systematic intravascular ultrasound imaging. $7 \mathrm{Am}$ Coll Cardiol. 1996;27(4):839-846.

6 Kirk R, Edwards LB, Kucheryavaya AY, et al. The Registry of the International Society for Heart and Lung Transplantation: thirteenth official pediatric heart transplantation report-2010. 7 Heart Lung Transplant. 2010;29:1119-1128.

7 Pahl ECA, Kuhn MA, eds. Allograft Vasculopathy: Detection, Risk Factors, Natural History, and Treatment. New York: Elsevier Mosby; 2007.

8 Nagji AS, Hranjec T, Swenson BR, et al. Donor age is associated with chronic allograft vasculopathy after adult heart transplantation: implications for donor allocation. Ann Thorac Surg. 2010;90: $168-175$.

9 Wilhelm MJ, Pratschke J, Beato F, et al. Activation of proinflammatory mediators in heart transplants from brain-dead donors: evidence from a model of chronic rat cardiac allograft rejection. Transplant Proc. 2002;34(6):2359-2360.

10 Herijgers $\mathrm{P}$, Leunens $\mathrm{V}$, Tjandra-Maga TB, Mubagwa K, Flameng $W$. Changes in organ perfusion after brain death in the rat and its relation to circulating catecholamines. Transplantation. 1996;62:330-335.

11 Atkinson C, Varela JC, Tomlinson S. Complement-dependent inflammation and injury in a murine model of brain dead donor hearts. Circ Res. 2009;105:1094-1101.

12 Szabo G, Buhmann V, Bahrle S, Vahl CF, Hagl S. Brain death impairs coronary endothelial function. Transplantation. 2002;73:1846-1848.

13 Stoica SC, Atkinson C, Satchithananda DK, et al. Endothelial activation in the transplanted human heart from organ retrieval to 3 months after transplantation: an observational study. 7 Heart Lung Transplant. 2005;24:593-601.

14 Valantine HA. Cardiac allograft vasculopathy: central role of endothelial injury leading to transplant “atheroma." Transplantation. 2003;76:891899.

15 Currie M, Zaki AM, Nejat S, Hirsch GM, Lee TD. Immunologic targets in the etiology of allograft vasculopathy: endothelium versus media. Transpl Immunol. 2008;19:120-126.

16 King CL, Devitt JJ, Lee TD, Hancock Friesen CL. Neutrophil mediated smooth muscle cell loss precedes allograft vasculopathy. 7 Cardiothorac Surg. 2010;5:52. 
17 Day JD, Rayburn BK, Gaudin PB, et al. Cardiac allograft vasculopathy: the central pathogenetic role of ischemia-induced endothelial cell injury. 7 Heart Lung Transplant. 1995;14(6 pt 2):S142S149.

18 Vessie EL, Hirsch GM, Lee TD. Aortic allograft vasculopathy is mediated by $\mathrm{CD} 8(+) \mathrm{T}$ cells in Cyclosporin A immunosuppressed mice. Transpl Immunol. 2005;15(1):35-44.

19 Wehner JR, Fox-Talbot K, Halushka MK, Ellis C, Zachary AA, Baldwin WM 3rd. B cells and plasma cells in coronaries of chronically rejected cardiac transplants. Transplantation. 2010;89:1141-1148.

20 Cunningham KS, Gotlieb AI. The role of shear stress in the pathogenesis of atherosclerosis. Lab Invest. 2005;85(1):9-23.

21 Takumi T, Yang EH, Mathew V, et al. Coronary endothelial dysfunction is associated with a reduction in coronary artery compliance and an increase in wall shear stress. Heart. 2010;96:773-778.

22 Sun N, Wood NB, Hughes AD, Thom SA, Yun Xu $\mathrm{X}$. Effects of transmural pressure and wall shear stress on LDL accumulation in the arterial wall: a numerical study using a multilayered model. $A m \mathcal{F}$ Physiol Heart Circ Physiol. 2007;292(6):H3148H3157.

23 Urschel S, Altamirano-Diaz LA, West LJ. Immunosuppression armamentarium in 2010: mechanistic and clinical considerations. Pediatr Clin North Am. 2010;57(2):433-457. Table of contents.

24 Addonizio LJ, Hsu DT, Douglas JF, et al. Decreasing incidence of coronary disease in pediatric cardiac transplant recipients using increased immunosuppression. Circulation. 1993;88(5 pt 2): II224-II229.

25 Eisen HJ, Kobashigawa J, Keogh A, et al. Threeyear results of a randomized, double-blind, controlled trial of mycophenolate mofetil versus azathioprine in cardiac transplant recipients. 7 Heart Lung Transplant. 2005;24:517-525.

26 Eisen HJ, Tuzcu EM, Dorent R, et al. Everolimus for the prevention of allograft rejection and vasculopathy in cardiac-transplant recipients. $N$ Engl $\mathcal{F}$ Med. 2003;349:847-858.

27 Mancini D, Pinney S, Burkhoff D, et al. Use of rapamycin slows progression of cardiac transplantation vasculopathy. Circulation. 2003;108:48-53.

28 Nwakanma LU, Williams JA, Weiss ES, Russell $\mathrm{SD}$, Baumgartner WA, Conte JV. Influence of pretransplant panel-reactive antibody on outcomes in 8160 heart transplant recipients in recent era. Ann Thorac Surg. 2007;84(5):1556-1562, discussion 62-63.

29 Girnita AL, Webber SA, Zeevi A. Anti-HLA alloantibodies in pediatric solid organ transplantation. Pediatr Transplant. 2006;10:146-153.

30 Di Filippo S, Girnita A, Webber SA, et al. Impact of ELISA-detected anti-HLA antibodies on pediatric cardiac allograft outcome. Hum Immunol. 2005;66:513-518.

31 Feingold B, Bowman P, Zeevi A, et al. Survival in allosensitized children after listing for cardiac transplantation. 7 Heart Lung Transplant. 2007; 26:565-571.

32 Irving C, Hasan A, Carter V, Gennery A, Parry G, Kirk R. Association between donor-specific HLA antibodies and adverse outcome following paediatric cardiac transplantation. 7 Heart Lung Transplant. 2009;28(2):S232.

33 Rossano JW, Morales DL, Denfield SW, et al. Impact of panel-reactive antibodies on long-term outcome in pediatric heart transplant patients: an analysis of the united network of organ sharing database. 7 Heart Lung Transplant. 2009;28(2): S232.

34 Urschel S, Campbell PM, Meyer SR, et al. Absence of donor-specific anti-HLA antibodies after ABO-incompatible heart transplantation in infancy: altered immunity or age? Am 7 Transplant. 2010;10:149-156.

35 Kuhn MA, Jutzy KR, Deming DD, et al. The medium-term findings in coronary arteries by intravascular ultrasound in infants and children after heart transplantation. $7 \mathrm{Am}$ Coll Cardiol. 2000;36(1):250-254.

36 Ameduri R, Zheng J, Schechtman K, et al. Abstract 13877: has late rejection decreased in pediatric heart transplantation in the current era? A multiinstitutional study. Circulation. 2010;122(25 suppl): A13877.

37 Pahl E, Naftel DC, Kuhn MA, et al. The impact and outcome of transplant coronary artery disease in a pediatric population: a 9-year multiinstitutional study. 7 Heart Lung Transplant. 2005; 24:645-651.

38 Mulla NF, Johnston JK, Vander Dussen L, et al. Late rejection is a predictor of transplant coronary artery disease in children. $7 \mathrm{Am}$ Coll Cardiol. 2001;37(1):243-250.

39 Mahle WT, Vincent RN, Berg AM, Kanter KR. Pravastatin therapy is associated with reduction in coronary allograft vasculopathy in pediatric heart transplantation. 7 Heart Lung Transplant. 2005; 24:63-66.

40 Nicolas RT, Kort HW, Balzer DT, et al. Surveillance for transplant coronary artery disease in infant, child and adolescent heart transplant recipients: an intravascular ultrasound study. 7 Heart Lung Transplant. 2006;25:921-927.

41 Zhang Q, Liang LW, Gjertson DW, et al. Development of posttransplant antidonor HLA antibodies is associated with acute humoral rejection and early graft dysfunction. Transplantation. 2005;79:591-598.

42 Holweg CT, Weimar W, Uitterlinden AG, Baan CC. Clinical impact of cytokine gene polymor- 
phisms in heart and lung transplantation. 7 Heart Lung Transplant. 2004;23:1017-1026.

43 Imhof BA, Dunon D. Leukocyte migration and adhesion. Adv Immunol. 1995;58:345-416.

44 Borozdenkova S, Smith J, Marshall S, Yacoub M, Rose M. Identification of ICAM-1 polymorphism that is associated with protection from transplant associated vasculopathy after cardiac transplantation. Hum Immunol. 2001;62:247-255.

45 Neumann FJ, Ott I, Gawaz M, et al. Cardiac release of cytokines and inflammatory responses in acute myocardial infarction. Circulation. 1995;92: $748-755$.

46 Kharazmi A, Nielsen H, Rechnitzer C, Bendtzen $\mathrm{K}$. Interleukin 6 primes human neutrophil and monocyte oxidative burst response. Immunol Lett. 1989;21:177-184.

47 Lou H, Kodama T, Wang YN, Katz N, Ramwell $\mathrm{P}$, Foegh ML. L-arginine prevents heart transplant arteriosclerosis by modulating the vascular cell proliferative response to insulin-like growth factor-I and interleukin-6. 7 Heart Lung Transplant. 1996;15:1248-1257.

48 Ganter U, Arcone R, Toniatti C, Morrone G, Ciliberto G. Dual control of C-reactive protein gene expression by interleukin-1 and interleukin-6. EMBO 7. 1989;8(12):3773-3779.

49 Ali MH, Schlidt SA, Chandel NS, Hynes KL, Schumacker PT, Gewertz BL. Endothelial permeability and IL-6 production during hypoxia: role of ROS in signal transduction. Am 7 Physiol. 1999;277(5 pt 1):L1057-L1065.

50 Fishman D, Faulds G, Jeffery R, et al. The effect of novel polymorphisms in the interleukin-6 (IL-6) gene on IL-6 transcription and plasma IL-6 levels, and an association with systemic-onset juvenile chronic arthritis. F Clin Invest. 1998;102:13691376.

51 Densem CG, Ray M, Hutchinson IV, Yonan N, Brooks NH. Interleukin-6 polymorphism: a genetic risk factor for cardiac transplant related coronary vasculopathy? 7 Heart Lung Transplant. 2005;24:559-565.

52 Holweg CT, Baan CC, Balk AH, et al. The transforming growth factor-beta1 codon 10 gene polymorphism and accelerated graft vascular disease after clinical heart transplantation. Transplantation. 2001;71:1463-1467.

53 Lawrence DA. Transforming growth factor-beta: a general review. Eur Cytokine Netw. 1996;7:363374.

54 Densem CG, Hutchinson IV, Yonan N, Brooks NH. Donor and recipient-transforming growth factor-beta 1 polymorphism and cardiac transplant-related coronary artery disease. Transpl Immunol. 2004;13:211-217.

55 Densem CG, Hutchinson IV, Yonan N, Brooks NH. Influence of tumor necrosis factor-alpha gene-308 polymorphism on the development of coronary vasculopathy after cardiac transplantation. 7 Heart Lung Transplant. 2001;20:1265-1273.

56 Wang P, Ba ZF, Chaudry IH. Administration of tumor necrosis factor-alpha in vivo depresses endothelium-dependent relaxation. Am 7 Physiol. 1994;266(6 pt 2):H2535-H2541.

57 Andreassen AK, Nordoy I, Simonsen S, et al. Levels of circulating adhesion molecules in congestive heart failure and after heart transplantation. Am 7 Cardiol. 1998;81:604-608.

58 Ternstrom L, Jeppsson A, Ricksten A, Nilsson F. Tumor necrosis factor gene polymorphism and cardiac allograft vasculopathy. $\mathcal{F}$ Heart Lung Transplant. 2005;24:433-438.

59 Benza RL, Passineau MJ, Anderson PG, Barchue JP, George JF. The role of fibrinolytic genes and proteins in the development of allograft vascular disease. 7 Heart Lung Transplant. 2011;30:935944.

60 Benza RL, Grenett HE, Bourge RC, et al. Gene polymorphisms for plasminogen activator inhibitor-1/tissue plasminogen activator and development of allograft coronary artery disease. Circulation. 1998;98:2248-2254.

61 Degen SJ, Rajput B, Reich E. The human tissue plasminogen activator gene. 7 Biol Chem. 1986;261 (15):6972-6985.

62 Dawson S, Hamsten A, Wiman B, Henney A, Humphries S. Genetic variation at the plasminogen activator inhibitor-1 locus is associated with altered levels of plasma plasminogen activator inhibitor-1 activity. Arterioscler Thromb. 1991;11: 183-190.

63 Lemstrom KB, Nykanen AI, Tikkanen JM, et al. Role of angiogenic growth factors in transplant coronary artery disease. Ann Med. 2004;36:184193.

64 Tambur AR, Pamboukian S, Costanzo MR, Heroux A. Genetic polymorphism in plateletderived growth factor and vascular endothelial growth factor are significantly associated with cardiac allograft vasculopathy. $\mathcal{F}$ Heart Lung Transplant. 2006;25:690-698.

65 Shahbazi M, Fryer AA, Pravica V, et al. Vascular endothelial growth factor gene polymorphisms are associated with acute renal allograft rejection. 7 Am Soc Nephrol. 2002;13(1):260-264.

66 Nykanen AI, Krebs R, Tikkanen JM, et al. Combined vascular endothelial growth factor and platelet-derived growth factor inhibition in rat cardiac allografts: beneficial effects on inflammation and smooth muscle cell proliferation. Transplantation. 2005;79:182-189.

67 Yousufuddin M, Yamani MH. The reninangiotensin hypothesis for the pathogenesis of cardiac allograft vasculopathy. Int 7 Cardiol. 2004; 95(2-3):123-127. 
68 Erinc K, Yamani MH, Starling RC, et al. The effect of combined Angiotensin-converting enzyme inhibition and calcium antagonism on allograft coronary vasculopathy validated by intravascular ultrasound. 7 Heart Lung Transplant. 2005;24:1033-1038.

69 Richter MH, Richter HR, Olbrich HG, Mohr FW. Two good reasons for an angiotensin-II type 1 receptor blockade with losartan after cardiac transplantation: reduction of incidence and severity of transplant vasculopathy. Transpl Int. 2003;16(1): 26-32.

70 Tiret L, Rigat B, Visvikis S, et al. Evidence, from combined segregation and linkage analysis, that a variant of the angiotensin I-converting enzyme (ACE) gene controls plasma ACE levels. Am 7 Hum Genet. 1992;51:197-205.

71 Arbustini E, Grasso M, Fasani R, et al. Angiotensin converting enzyme gene deletion allele is independently and strongly associated with coronary atherosclerosis and myocardial infarction. Br Heart 7 . 1995;74:584-591.

72 Cambien F, Poirier O, Lecerf L, et al. Deletion polymorphism in the gene for angiotensinconverting enzyme is a potent risk factor for myocardial infarction. Nature. 1992;359(6396): 641-644.

73 Pethig K, Heublein B, Hoffmann A, Borlak J, Wahlers T, Haverich A. ACE-gene polymorphism is associated with the development of allograft vascular disease in heart transplant recipients. 7 Heart Lung Transplant. 2000;19:1175-1182.

74 Cunningham DA, Crisp SJ, Barbir M, Lazem F, Dunn MJ, Yacoub MH. Donor ACE gene polymorphism: a genetic risk factor for accelerated coronary sclerosis following cardiac transplantation. Eur Heart 7. 1998;19:319-325.

75 Kobashigawa JA, Katznelson S, Laks H, et al. Effect of pravastatin on outcomes after cardiac transplantation. N Engl f Med. 1995;333:621627.

76 Seipelt IM, Crawford SE, Rodgers S, et al. Hypercholesterolemia is common after pediatric heart transplantation: initial experience with pravastatin. 7 Heart Lung Transplant. 2004;23:317-322.

77 Singh TP, Naftel DC, Webber S, et al. Hyperlipidemia in children after heart transplantation. 7 Heart Lung Transplant. 2006;25:1199-1205.

78 Escobar A, Ventura HO, Stapleton DD, et al. Cardiac allograft vasculopathy assessed by intravascular ultrasonography and nonimmunologic risk factors. Am $\mathcal{F}$ Cardiol. 1994;74:1042-1046.

79 Stampfer MJ, Sacks FM, Salvini S, Willett WC, Hennekens CH. A prospective study of cholesterol, apolipoproteins, and the risk of myocardial infarction. N Engl 7 Med. 1991;325:373-381.

80 Hedman M, Pahlman R, Sundvall J, et al. Low HDL-C predicts the onset of transplant vasculopa- thy in pediatric cardiac recipients on pravastatin therapy. Pediatr Transplant. 2007;11:481-490.

81 Malinow MR. Hyperhomocyst(e)inemia. A common and easily reversible risk factor for occlusive atherosclerosis. Circulation. 1990;81(6):20042006.

82 Genest JJ Jr, McNamara JR, Salem DN, Wilson PW, Schaefer EJ, Malinow MR. Plasma homocys$\mathrm{t}(\mathrm{e})$ ine levels in men with premature coronary artery disease. 7 Am Coll Cardiol. 1990;16(5):11141119.

83 Mayer EL, Jacobsen DW, Robinson K. Homocysteine and coronary atherosclerosis. $7 \mathrm{Am}$ Coll Cardiol. 1996;27:517-527.

84 Cook RC, Tupper JK, Parker S, et al. Effect of immunosuppressive therapy, serum creatinine, and time after transplant on plasma total homocysteine in patients following heart transplantation. 7 Heart Lung Transplant. 1999;18:420-424.

85 Parisi F, Kost-Byerly S, Saponara I, Di Donato R, Di Liso G. Elevated plasma homocysteine concentrations after pediatric heart transplantations. Transpl Int. 2000;13(suppl 1):S235-S239.

86 Kutschka I, Pethig K, Harringer W, Haverich A, Struber M. Increased plasma homocysteine concentrations accelerate cardiac allograft vasculopathy. 7 Heart Lung Transplant. 2004;23:12601265.

87 Miner SE, Cole DE, Evrovski J, Verma A, Daly PA, Ross HJ. Hyperhomocysteinemia and transplant coronary artery disease in cardiac transplant recipients. Clin Transplant. 2001;15:258-262.

88 Welch GN, Loscalzo J. Homocysteine and atherothrombosis. N Engl f Med. 1998;338:1042-1050.

89 Tawakol A, Omland T, Gerhard M, Wu JT, Creager MA. Hyperhomocyst(e)inemia is associated with impaired endothelium-dependent vasodilation in humans. Circulation. 1997;95(5): 1119-1121.

90 Parisi F, Danesi H, Di Ciommo V, et al. Treatment of hyperhomocysteinemia in pediatric heart transplant recipients. 7 Heart Lung Transplant. 2003;22:778-783.

91 Potena L, Grigioni F, Magnani G, et al. Homocysteine-lowering therapy and early progression of transplant vasculopathy: a prospective, randomized, IVUS-based study. Am $\mathcal{F}$ Transplant. 2005;5(9):2258-2264.

92 Potena L, Grigioni F, Masetti M, et al. Long-term effect of folic acid therapy in heart transplant recipients: follow-up analysis of a randomized study. Transplantation. 2008;85:1146-1150.

93 Chen R, Xiong S, Yang Y, Fu W, Wang Y, Ge J. The relationship between human cytomegalovirus infection and atherosclerosis development. Mol Cell Biochem. 2003;249(1-2):91-96.

94 Grattan MT, Moreno-Cabral CE, Starnes VA, Oyer PE, Stinson EB, Shumway NE. Cytomega- 
lovirus infection is associated with cardiac allograft rejection and atherosclerosis. FAMA. 1989;261: 3561-3566.

95 Sambiase NV, Higuchi ML, Nuovo G, et al. CMV and transplant-related coronary atherosclerosis: an immunohistochemical, in situ hybridization, and polymerase chain reaction in situ study. Mod Pathol. 2000;13:173-179.

96 Valantine HA. Role of CMV in transplant coronary artery disease and survival after heart transplantation. Transpl Infect Dis. 1999;1(suppl 1): 25-30.

97 Fateh-Moghadam S, Bocksch W, Wessely R, Jager G, Hetzer R, Gawaz M. Cytomegalovirus infection status predicts progression of heart-transplant vasculopathy. Transplantation. 2003;76:1470-1474.

98 Hussain T, Burch M, Fenton MJ, et al. Positive pretransplantation cytomegalovirus serology is a risk factor for cardiac allograft vasculopathy in children. Circulation. 2007;115:1798-1805.

99 Simmonds J, Fenton M, Dewar C, et al. Endothelial dysfunction and cytomegalovirus replication in pediatric heart transplantation. Circulation. 2008;117:2657-2661.

100 Mahle WT, Fourshee MT, Naftel DM, et al. Does cytomegalovirus serology impact outcome after pediatric heart transplantation? 7 Heart Lung Transplant. 2009;28:1299-1305.

101 Shirali GS, Ni J, Chinnock RE, et al. Association of viral genome with graft loss in children after cardiac transplantation. N Engl f Med. 2001; 344:1498-1503.

102 Bowles NE, Shirali GS, Chinnock RE, Rosenthal GL, Towbin JA. Association of viral genome with transplant coronary arteriopathy and graft loss in children following cardiac transplantation. 7 Heart Lung Transplant. 2001;20:198.

103 Moulik M, Breinholt JP, Dreyer WJ, et al. Viral endomyocardial infection is an independent predictor and potentially treatable risk factor for graft loss and coronary vasculopathy in pediatric cardiac transplant recipients. 7 Am Coll Cardiol. 2010; 56:582-592.

104 Graham JA, Wilkinson RA, Hirohashi T, et al. Viral infection induces de novo lesions of coronary allograft vasculopathy through a natural killer celldependent pathway. Am 7 Transplant. 2009;9(11): 2479-2484.

105 Chobanian AV, Bakris GL, Black HR, et al. The Seventh Report of the Joint National Committee on Prevention, Detection, Evaluation, and Treatment of High Blood Pressure: the JNC 7 report. 7AMA. 2003;289:2560-2572.

106 Lewington S, Clarke R, Qizilbash N, Peto R, Collins R. Age-specific relevance of usual blood pressure to vascular mortality: a meta-analysis of individual data for one million adults in 61 prospective studies. Lancet. 2002;360(9349):1903-1913.

107 Radovancevic B, Poindexter S, Birovljev S, et al. Risk factors for development of accelerated coronary artery disease in cardiac transplant recipients. Eur 7 Cardiothorac Surg. 1990;4:309-312, discussion 13.

108 Schroeder JS, Gao SZ, Alderman EL, et al. A preliminary study of diltiazem in the prevention of coronary artery disease in heart-transplant recipients. N Engl f Med. 1993;328:164-170.

109 O'Neill BJ, Pflugfelder PW, Singh NR, Menkis AH, McKenzie FN, Kostuk WJ. Frequency of angiographic detection and quantitative assessment of coronary arterial disease one and three years after cardiac transplantation. Am 7 Cardiol. 1989;63:1221-1226.

110 Shaddy RE, Naftel DC, Kirklin JK, et al. Outcome of cardiac transplantation in children. Survival in a contemporary multi-institutional experience. Pediatric Heart Transplant Study. Circulation. 1996;94(9 suppl):II69-II73 .

111 Kuhn CC, Chinnock RE, Deming DD, Razzouk AJ, Bailey LL. The presence of cardiac allograft vasculopathy in infant and pediatric heart transplant recipients: a 10 -year intravascular ultrasound study. 7 Heart Lung Transplant. 2009;28(2S1):S124.

112 Urschel S, Ryan LA, Jeyakanthan M, Larsen IM, West LJ. Impact of B-Cell memory on development of donor-specific tolerance in ABOincompatible heart transplantation in early childhood. 7 Heart Lung Transplant. 2010;29:100.

113 Rijkers GT, Sanders EAM, Breukels MA, Zegers BJM. Infant B-cell response to polysaccharide determinants. Vaccine. 1998;16:1396-1400.

114 West LJ, Pollock-Barziv SM, Dipchand AI, et al. $\mathrm{ABO}$-incompatible heart transplantation in infants. N Engl 7 Med. 2001;344:793-800.

115 Dipchand AI, Pollock BarZiv SM, Manlhiot C, West LJ, VanderVliet M, McCrindle BW. Equivalent outcomes for pediatric heart transplantation recipients: $\mathrm{ABO}-$ blood group incompatible versus ABO-compatible. Am F Transplant. 2010;10:389397.

116 Ogle BM, West LJ, Driscoll DJ, et al. Effacing of the $T$ cell compartment by cardiac transplantation in infancy. 7 Immunol. 2006;176(3):1962-1967.

117 Madhok AB, Chandrasekran A, Parnell V, Gandhi M, Chowdhury D, Pahwa S. Levels of recent thymic emigrant cells decrease in children undergoing partial thymectomy during cardiac surgery. Clin Diagn Lab Immunol. 2005;12:563-565.

118 Chin C, Naftel D, Pahl E, et al. Cardiac re-transplantation in pediatrics: a multiinstitutional study. 7 Heart Lung Transplant. 2006; 25:1420-1424. 